\title{
Palatine tonsillar metastasis of rectal adenocarcinoma: a case report and literature review
}

Hao Wang and Ping Chen ${ }^{*}$

\begin{abstract}
Cases of primary colorectal adenocarcinoma metastasized to the palatine tonsil are extremely rare. To the best of our knowledge, only 10 cases have thus far been previously documented in the English literature. A 37-year-old Chinese woman presented with a right palatine tonsil swelling and odynophagia 5 months after a surgical resection of rectal adenocarcinoma was performed. The patient underwent a tonsillectomy, and a metastatic poorly differentiated adenocarcinoma from a colorectal origin was revealed by immunohistochemical analysis. The manner in which tonsillar metastases are involved remains unknown and should be further studied. Here, we report a new case, briefly summarize these 10 cases and review the literature.
\end{abstract}

Keywords: Tonsil neoplasm, Metastasis, Rectal neoplasm, Adenocarcinoma, Immunohistochemistry

\section{Background}

The most common sites of distant metastases from primary colorectal carcinoma are in the liver, lung, and brain, and less commonly in the bone, ovary, and adrenal gland. Metastasis to palatine tonsil from a primary colorectal carcinoma is an extremely rare event. Only 10 cases have thus far been previously documented in the English literature. Hematogenous dissemination is a probable explanation for the mechanism of metastasis to the palatine tonsils [1], as well as the suggestion of a retrograde cervical lymphatic spread through the thoracic duct [2].

A metastatic tumor in an unusual site may sometimes be troublesome to distinguish between a synchronous or metachronous primary cancer and a metastatic disease, especially when it is asymptomatic. In this paper, we report the case of a 37-year-old Chinese woman with a metastasis to the right palatine tonsil from a rectal adenocarcinoma and review the literature.

\section{Case presentation}

A 37-year-old Chinese woman was evaluated for right tonsil swelling and a sore throat in our hospital. She was

\footnotetext{
*Correspondence: chen86ky@126.com

Department of Gastrointestinal Surgery, Northern Jiangsu People's Hospital, Yangzhou University, Yangzhou, Jiangsu Province 225001, PR China
}

diagnosed in September 2011 with rectal cancer revealed by generalized peritonitis evoked by tumor perforation. At diagnosis, the preoperative evaluation did not show distant metastasis (M0). The patient underwent an urgent exploratory laparotomy. The tumor measuring 10.0 $\mathrm{cm} \times 4.0 \mathrm{~cm} \times 3.5 \mathrm{~cm}$ was identified at the anterior rectal wall under the peritoneal reflection intraoperatively. A low anterior resection using a total mesorectal excision technique was performed, with a colostomy using noninflamed descending colon, and the divided end of the rectum was closed. The excised specimen contained a poorly differentiated adenocarcinoma invading into nonperitonealized perirectal fat with negative surgical margins (T3). Nine regional lymph nodes were positive for tumor extension (N2b). The tumor was classified as stage IIIc disease based on the American Joint Committee on Cancer TNM staging system.

The patient did not receive any adjuvant radiotherapy and chemotherapy postoperatively. In March 2012 the patient was admitted to our department on account of abdominal pain and distension triggered by small bowel obstruction. A nonenhanced abdominal computed tomography scan revealed enlarged para-aortic lymph nodes measuring approximately $4 \mathrm{~cm}$ in diameter (Figure 1), which compressed the left upper ureter (Figure 2). No evidence of cerebral and visceral metastasis or 


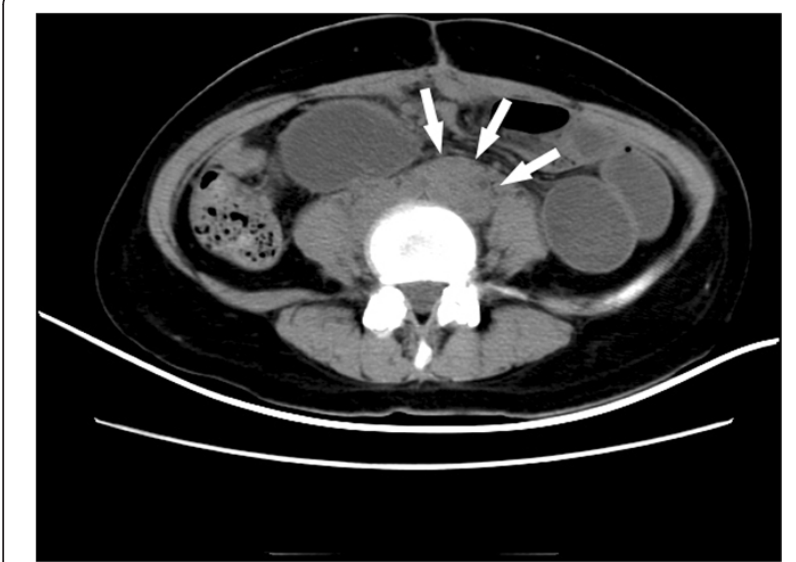

Figure 1 Nonenhanced abdominal computed tomography scan. The scan revealed para-aortic lymph node enlargement measuring approximately $4 \mathrm{~cm}$ in diameter (arrows)

mediastinal lymph nodes was identified by computed tomography scan of the brain, chest, and abdomen.

In the following days, the patient complained of swelling of her right tonsil and odynophagia. She did not report symptoms of dysphagia or tonsillitis. Physical examination revealed an ulcerated mass measuring about $1 \mathrm{~cm}$ in maximum diameter, on the upper part of her right palatine tonsil. There were no palpable cervical lymph nodes. The rest of the physical examination was unremarkable. Routine laboratory parameters including the complete blood count, erythrocyte sedimentation rate, C-reactive protein level, liver and pancreas enzymes, and tumor markers (carcinoembryonic antigen, carcinoma antigen 125, carcinoma antigen 199, and $\alpha$-fetoprotein) were all within normal limits. A punch biopsy was taken for histological examination, which showed a poorly differentiated adenocarcinoma (Figure 3). The patient underwent a palliative

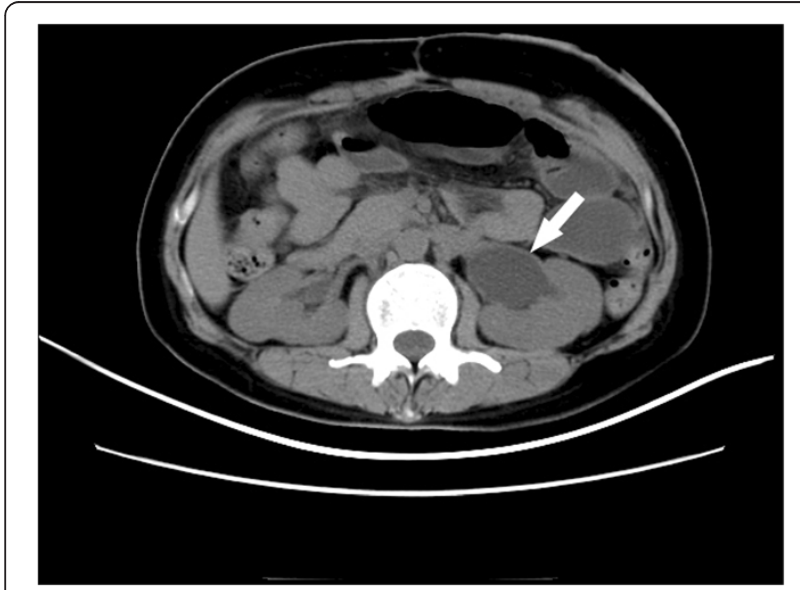

Figure 2 Enlarged para-aortic lymph nodes compressed the left upper ureter causing left ureteral obstruction and hydronephrosis. Arrow, left ureteral obstruction.

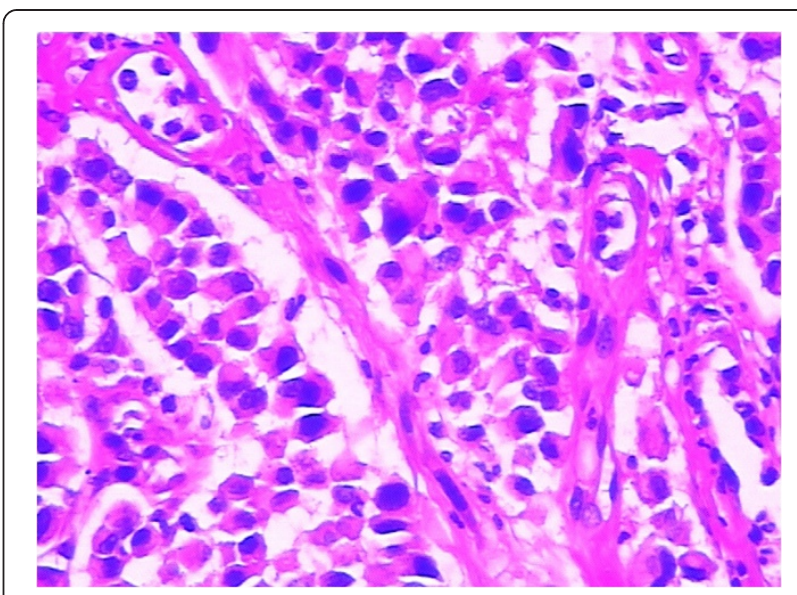

Figure 3 Microscopic section of the biopsy tissue showed abundant heterogenic cells with a neoplastic gland formation. $H$ \& E, magnification $\times 200$.

right tonsillectomy without neck dissection. Microscopic examination of the resected specimen disclosed surface squamous epithelium with extensive infiltration of the tonsillar lamina propria by abundant malignant small glandular cells (Figures 4 and 5). Immunohistochemical analysis results of tumor cells are presented in Table 1 . These features confirmed the diagnosis of metastatic poorly differentiated adenocarcinoma of the right palatine tonsil identical to the colorectal primary. At the time of submission of the present manuscript the patient was still alive, 9 months after the diagnosis of metastatic disease.

\section{Discussion}

Metastases to tonsils from nonhematological malignant neoplasms are rare events [3], accounting for only $0.8 \%$

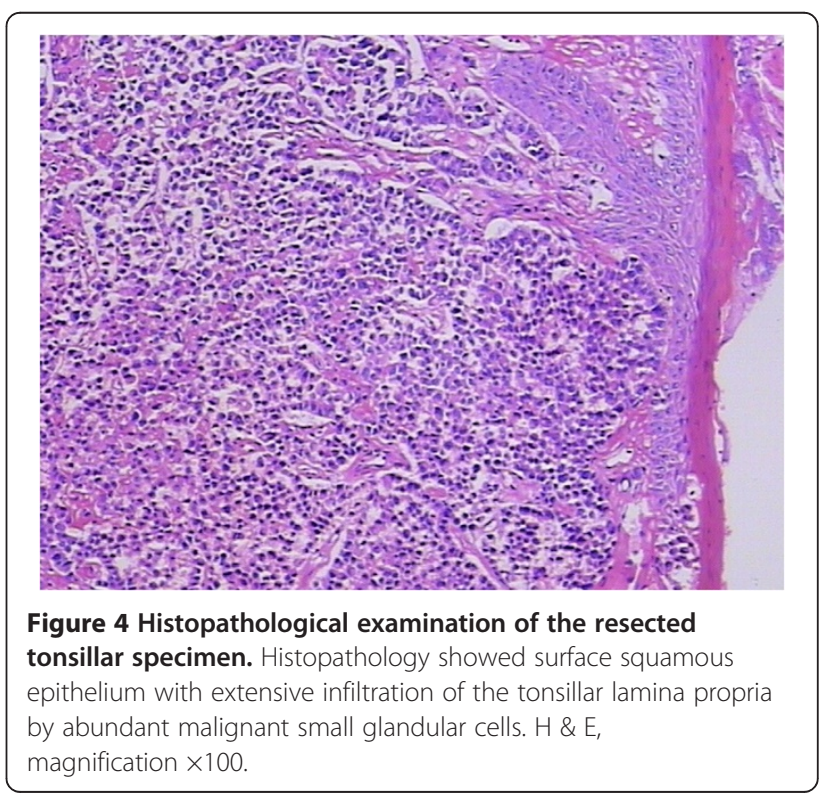




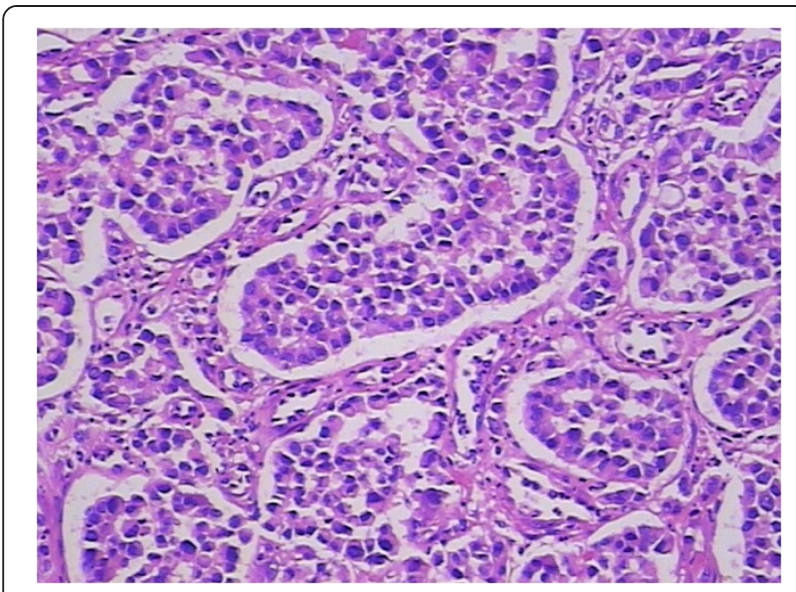

Figure 5 Histopathological feature of the tonsillar tumor: abundant malignant small glandular cells. $\mathrm{H} \& \mathrm{E}$, magnification $\times 200$

of all tonsillar malignancies [4]. Malignant melanoma [5], renal cell carcinoma [2], breast carcinoma [6], and lung carcinoma [7] have been described as the most common primaries of tonsillar metastases. Adenocarcinoma of the stomach [8] and carcinoma of the pancreas [9] and seminomas [10] are less common primary sites. Sporadic cases of tonsillar metastasis have been reported from prostate carcinoma [11], gall bladder carcinoma [12], anaplastic thyroid carcinoma [13], Merkel cell carcinoma [14], choriocarcinoma [15], and malignant mesothelioma [16].

Metastasis from a primary colorectal adenocarcinoma to the palatine tonsil is an extremely rare event. We searched PubMed, MEDLINE, and Google Scholar, from inception to December 2012, using the terms 'colorectal/ colon/colonic/rectum/rectal'; 'cancer/ carcinoma/adenocarcinoma'; 'palatine tonsil/tonsil'; and 'metastasis'. The literature was limited to English-language case reports.

Table 1 Immunohistochemical analysis results of palatine tonsillar tumor cells

\begin{tabular}{cccccc}
\hline Antibody & P/N & Antibody & P/N & Antibody & P/N \\
\hline bcl-6 & - & CD56 & - & EMA & +++ \\
CD1a & - & CD79a & - & Granzyme B & - \\
CD10 & - & CDX-2 & +++ & mum-1 & - \\
CD138 & + & CK20 & ++ & p63 & - \\
CD20 & - & CK34ßE12 & - & Perforin & - \\
CD3 & - & CK5/6 & - & S100 & - \\
CD45-LCA & - & CK7 & - & TdT & - \\
CD45Ro & - & CKpan & ++ & villin & +++ \\
\hline
\end{tabular}

$\mathrm{P} / \mathrm{N}$ positive/negative, CK cytokeratin, EMA epithelial membrane antigen, mum-1, melanoma-associated antigen (mutated) $1 \mathrm{TdT}$ terminal deoxynucleotidyl transferase, - , no cells positive by immunohistochemistry (IHC); \pm , sometimes weak positive, sometimes negative by $\mathrm{IHC} ;+,<25 \%$ of cells positive by $\mathrm{IHC}$; ,++ 25 to $50 \%$ of cells positive by IHC;,$+++>50 \%$ of cells positive by IHC.
References of included articles were also searched. Only 10 cases have been documented previously. We present a summary of all these 10 cases, as well as the present case, to highlight their clinicopathological profiles (Table 2). In a total of 11 patients, the age ranged from 36 to 81 years (mean: 53.5 years; median: 53 years), having a male-to-female ratio of 1.75:1 (7 vs. 4). In our case, the patient was a 37 -year-old woman with a primary rectal adenocarcinoma that had metastasized to the right palatine tonsil. This is the youngest female patient to be reported. The metastases to palatine tonsils have a tendency to manifest unilaterally, while the left side (7/11) was more commonly involved than the right $(4 / 11)$. Involvement of both sides was not observed. Contradictorily, it had been reported that malignant melanoma metastatic to the tonsil usually manifests bilaterally $[2,8]$. Of the 11 cases, seven patients had enlarged cervical lymph nodes when the palatine tonsil mass was found, while seven patients had primary lesions with metastatic regional lymph nodes, and one patient had metastatic evidence in the liver, two patients in the lung, three patients in the brain, three patients in bone, two patients in the mediastinum, two patients in the subcutis, and one patient in the axilla. Metastatic palatine tonsillar adenocarcinoma is a systematic malignancy that harbors a poor prognosis irrespective of the differentiation of the primary tumor and stage of the disease. Even though only 10 cases have been reported, the life expectancy ranged from 6 to 15 months, no matter whether the patient is treated by palliative chemoradiotherapy or tonsillectomy.

In the metastatic process, tonsillar involvement could either be the first station or a part of widespread systematic distant metastases. Although the pathway by which malignancies metastasized to the tonsil remains controversial and difficult to determine, some hypotheses have been built. Brownson and colleagues suggested that retrograde cervical lymphatic spread through the thoracic duct may be a potential mechanism, since the palatine tonsil does not have afferent lymphatic vessels [2]. On the other hand, hematogenous spread to the tonsil may occur through the systematic arterial blood flow passing through the lungs. Or tumor cells can reach the brain or head and neck region bypassing the lungs via venous blood flow through Batson's plexus [1]. In the present case, evidence of metastases to the liver, lungs, brain, and bone were not observed and no cervical lymphadenopathy was palpated -metastasis to the unilateral palatine tonsil through Batson's plexus may therefore be a more reasonable explanation.

Malignancies of the palatine tonsil are unusual. Squamous epithelial carcinomas and lymphomas are generally observed in this area. In the present case, the palatine tonsillar tumor cells shown a glandular epithelial phenotype histologically (Figure 5), and were negative for both 
Table 2 Clinicopathological features of reported cases of metastatic palatine tonsil tumor of colorectal primary

\begin{tabular}{|c|c|c|c|c|c|c|c|c|}
\hline $\begin{array}{l}\text { Case } \\
\text { (reference) }\end{array}$ & $\begin{array}{l}\text { Sex/age } \\
\text { (years) }\end{array}$ & Side & Primary site & Differentiation & Stage & $\begin{array}{l}\text { Interval } \\
\text { (months) }\end{array}$ & Other metastases & $\begin{array}{l}\begin{array}{l}\text { Follow-up } \\
\text { (months) }\end{array} \\
\end{array}$ \\
\hline $1[17]$ & $F / 55$ & Right & Rectum & Well & NA & 84 & Mediastinum & NA \\
\hline $2[18]$ & M/65 & Left & $\begin{array}{l}\text { Transverse } \\
\text { colon }\end{array}$ & Poorly & NA & 0 & $\begin{array}{l}\text { Para-aortic LN, bone, } \\
\text { scalp }\end{array}$ & 6 \\
\hline $3[19]$ & M/36 & Right & Rectum & Signet-ring cell & Dukes C & 24 & NA & 15 alive \\
\hline $4[20]$ & $F / 81$ & Left & Hepatic flexure & Moderately & NA & 0 & Lung, liver, bone & 12 \\
\hline $5[21]$ & $M / 53$ & Right & Rectum & Poorly & Dukes C2 & 24 & Brain & 6 alive \\
\hline $6[22]$ & $\mathrm{M} / 45$ & Left & Rectum & Signet-ring cell & NA & 0 & Subcutaneous, bone & 6 \\
\hline 7 [23] & $M / 44$ & Left & Cecum & Signet-ring cell & NA & 0 & NA & NA \\
\hline $8[24]$ & $\mathrm{M} / 53$ & Left & $\begin{array}{l}\text { Ascending } \\
\text { colon }\end{array}$ & Moderately & T3N1M0 & 19 & Brain & 13 alive \\
\hline 9 [1] & $F / 76$ & Left & Splenic flexure & Signet-ring cell & T3N2M0 & 12 & Brain, right axilla & NA \\
\hline $10[25]$ & $M / 43$ & Left & Left colon & Moderately & T4aN2bM0 & 12 & Lung, mediastinum & NA \\
\hline Present case & $F / 37$ & Right & Rectum & Poorly & $\mathrm{T} 3 \mathrm{~N} 2 \mathrm{bM} 0$ & 5 & Para-aortic LN & 9 alive \\
\hline
\end{tabular}

F female, $\mathrm{M}$ male, Well, well differentiated adenocarcinoma; moderately, moderately differentiated adenocarcinoma; poorly, poorly differentiated adenocarcinoma; Signet-ring cell, signet-ring cell carcinoma; interval, time between the diagnosis of colorectal carcinoma and the development of metastasis to the palatine tonsil; LN lymph nodes, NA not available.

squamous epithelial carcinoma markers [cytokeratin (CK) 34.3E12, CK5/6, and p63] and lymphoma markers [bcl-6, CD1a, CD10, CD20, CD3, CD45-LCA, CD45Ro, CD56, $\mathrm{CD} 79 \mathrm{a}$, granzyme $\mathrm{B}$, melanoma-associated antigen (mutated) 1 , perforin, and terminal deoxynucleotidyl transferase] immunohistochemically (Table 1 ). Since there is no glandular epithelium in the palatine tonsil, a metastatic adenocarcinoma should be incorporated into the differential diagnosis. Adenocarcinoma of unknown primary often occurs in clinical practice. Even in the era of advanced imaging techniques and molecular tests, identification of the site of origin for metastatic adenocarcinoma frequently poses a challenge to clinicians and pathologists, and may lead to different therapeutic consequences. Immunohisto-

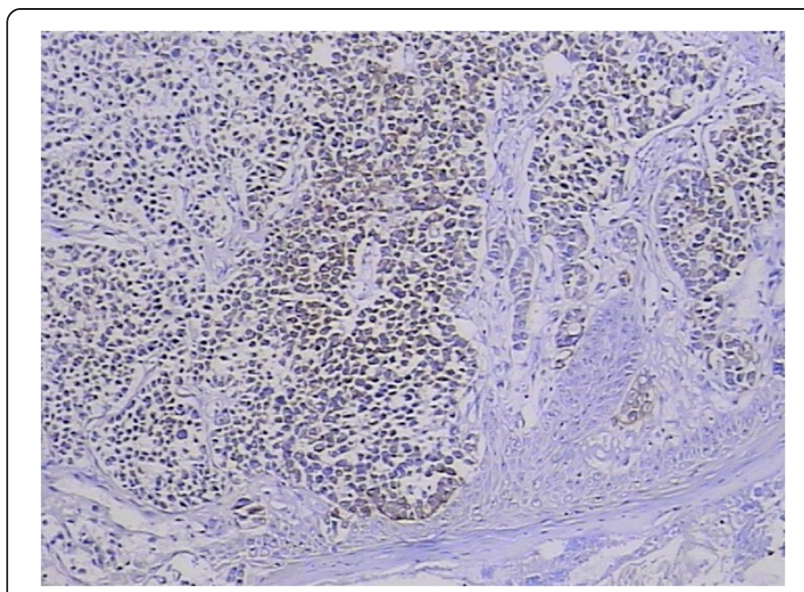

Figure 6 Tumor cytoplasm was cytokeratin 20-positive.

3,3'-Diaminobenzidine, magnification $\times 100$. chemical analysis remains a mainstay choice in identifying the histological origin of palatine tonsillar tumor with an occult primary. Although only few of tumor markers are very specific and have high sensitivity, several markers with moderate specificity are available, and when used in panels the discriminating capacity of these markers may be sufficient. The different expression patterns of CK20, CK7, CDX-2 and villin can be useful [26,27]. Given that $78 \%$ of adenocarcinomas of the upper gastrointestinal tract express both CK20 and CK7, most colorectal adenocarcinomas are positive for CK20 but negative for CK7 $[26,27]$. Further, metastatic lung adenocarcinoma shows a respiratory-type phenotype (CK20-/CK7+/ CDX-2-/ villin-), while metastatic colorectal adenocarcinoma

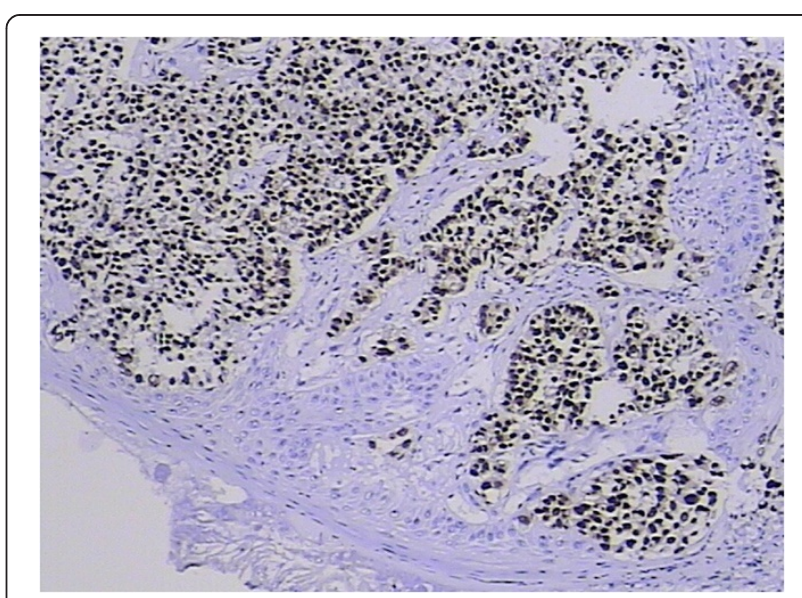

Figure 7 Tumor cell nucleus was positive for CDX-2.

3,3'-Diaminobenzidine, magnification $\times 100$. 


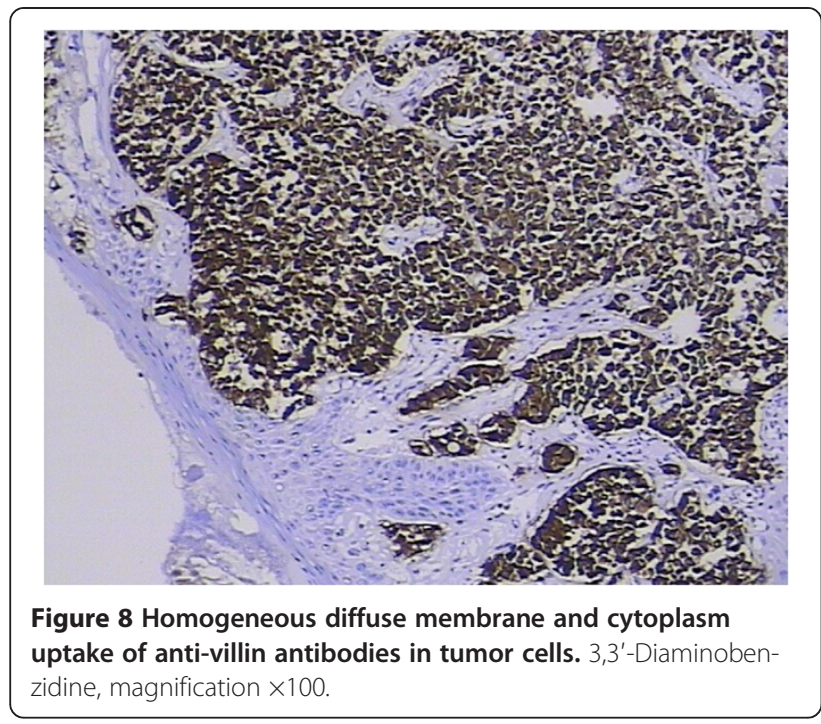

shows an intestinal-type phenotype (CK20+/CK7-/CDX$2+/$ villin+, as in our case; Figures 6, 7, 8 and 9) [28].

\section{Conclusions}

Metastatic palatine tonsil cancer from a primary colorectal adenocarcinoma is an extremely rare malignancy with a poor prognosis, and may lay a pitfall for clinicians. Immunohistochemical examination should therefore be performed. Immunomarkers including CK20, CK7, CDX-2, and villin are facilities in immunohistochemistry examination. The route of metastasis to the tonsil remains unclear and should been studied further.

\section{Consent}

Written informed consent was obtained from the patient for publication of this case report and any accompanying

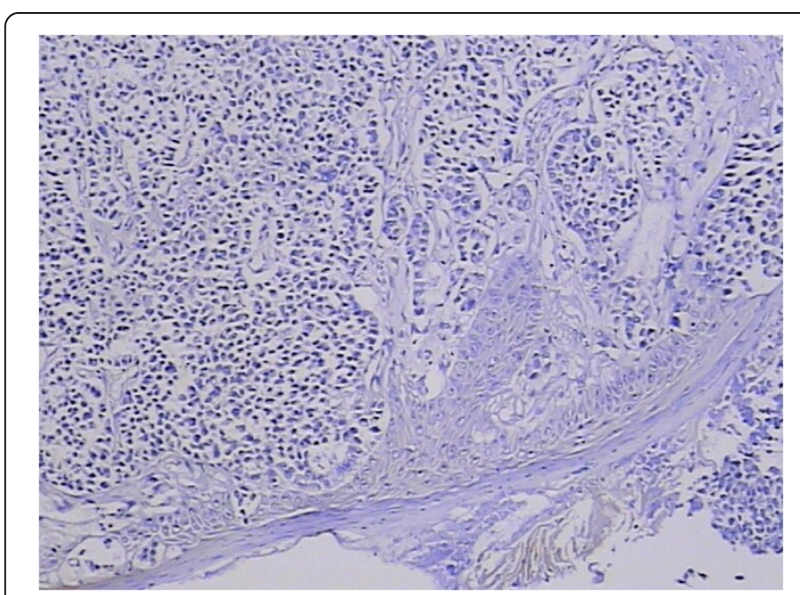

Figure 9 Tumor cells were negative for cytokeratin 7.

3,3'-Diaminobenzidine, magnification $\times 100$. images. A copy of the written consent is available for review by the Editor-in-Chief of this journal.

\section{Abbreviations \\ CK: Cytokeratin; H \& E: Hematoxylin and eosin.}

\section{Competing interests}

The authors declare that they have no competing interests.

\section{Authors' contributions}

HW performed the majority of this study and drafted the manuscript. PC provided the collection of material from the database. All authors read and approved the final manuscript.

Received: 20 December 2012 Accepted: 12 May 2013

Published: 25 May 2013

\section{References}

1. Park KK, Park YW: Tonsillar metastasis of signet-ring cell adenocarcinoma of the colon. Ear Nose Throat J 2010, 89:376-377.

2. Brownson RJ, Laques WE, LaMonte SE, Zollinger WK: Hypernephroma metastatic to the palatine tonsils. Ann Otol Rhinol Lanyngol 1979, 88:235-240.

3. Kleinschmidt HJ: Tonsillen Metastasen bei primaren Bronchial und Magenkarzinom. Z Laryngol Rhinol Otol Zhre Grenzgeb 1966, 45:389-394.

4. Crawford BE, Callihan MD, Corio RL, Hyams VJ, Karnei RF: Oral pathology. Otolaryngol Clin North Am 1979, 12:29-43.

5. Aydogan LB, Myers JN, Myers EN, Kirkwood J: Malignant melanoma metastatic to the tonsil. Laryngoscope 1996, 106:313-316.

6. Tueche SG, Nguyen $\mathrm{H}$, Larsimont D, Andry G: Late onset of tonsillar metastasis from breast cancer. Eur J Surg Oncol 1999, 25:439-440.

7. Seddon DJ: Tonsillar metastasis at presentation of small cell carcinoma of the lung. J $R$ Soc Med 1989, 82:688.

8. Benito I, Alvarez-Gago T, Morais D: Tonsillar metastasis from adenocarcinoma of the stomach. J Laryngol Otol 1996, 110:291-293.

9. Maor E, Tovi F, Sacks M: Carcinoma of the pancreas presenting with bilateral tonsillar metastasis. Ann Otol Rhinol Laryngol 1983, 92:192-195.

10. Siniakov BS: A case of metastasis of seminoma to the palatine tonsil. Vestn Otorinolaringol 1963, 25:99-101.

11. Millar EK, Jones RV, Lang S: Prostatic adenocarcinoma metastatic to the palatine tonsil: a case report. J Laryngol Otol 1994, 108:178-180.

12. Asami K, Yokoi H, Hattori T, Rao AJ, Yanagita N: Metastatic gall bladder carcinoma of the palatine tonsil. J Laryngol Otol 1989, 103:211-213.

13. Hadar T, Mor C, Har-El G, Sidi J: Anaplastic thyroid carcinoma metastatic to the tonsil. J Laryngol Otol 1987, 101:953-956.

14. Tesei F, Farneti G, Gavicchi O, Antonelli P, Zanetti G, Leone O: A case report of Merkel-cell carcinoma metastatic to the tonsil. J Laryngol Otol 1992, 106:1100-1102.

15. Kutty MK, Shenoy AV: Metastatic choriocarcinoma of the tonsil following hysterectomy for invasive mole and a period of 'inactivity' of trophoblastic tissue: case report. Oral Surg Oral Med Oral Pathol 1971, 32:248-252.

16. Hefer T, Danino J, Joachims HZ, Groisman GM: Metastatic malignant mesothelioma to the tonsil. Otolanyngol Head Neck Surg 1997, 116:684-688.

17. Sellars SL: Metastatic tumours of the tonsil. J Lanyngol Otol 1971, 85:289-292.

18. Low WK, Sng I, Balakrishnan A: Palatine tonsillar metastasis from carcinoma of the colon. J Laryngol Otol 1994, 108:449-451.

19. Wang WS, Chiou TJ, Pan CC, Chen WY, Chen PM: Signetring cell carcinoma of the rectum with tonsillar metastasis: a case report. Zhonghua Yixue Zazhi (Taipei) 1996, 58:209-212.

20. Vasilevsky CA, Abou-Khalil S, Rochon L, Frenkiel S, Black MJ: Carcinoma of the colon presenting as tonsillar metastasis. J Otolanyngol 1997, 26:325-326

21. Goldenberg D, Golz A, Arie YB, Joachims HZ: Adenocarcinoma of the rectum with metastasis to the palatine tonsil. Otolaryngol Head Neck Surg 1999, 121:653-654

22. Vauléon E, De Lajarte-Thirouard AS, Le Prisé E, Guihaire P, Raoul JL: Tonsillar metastasis revealing signet-ring cell carcinoma of the rectum. Gastroenterol Clin Biol 2005, 29:70-72.

23. Güvenç MG, Ada $M$, Acioğlu E, Pamukçu M: Tonsillar metastasis of primary signet-ring cell carcinoma of the cecum. Auris Nasus Larynx 2006, 33:85-88. 
24. Sheng $L M$, Zhang $L Z, X u H M$, Zhu Y: Ascending colon adenocarcinoma with tonsillar metastasis: a case report and review of the literature. World J Gastroenterol 2008, 14:7138-7140.

25. Lemay F, Cervera P, de Gramont A: A man with colon cancer and tonsil swelling. Tonsillar metastasis from colon cancer. Gastroenterology 2012, 142:1423-1625.

26. Kende Al, Carr NJ, Sobin LH: Expression of cytokeratins 7 and 20 in carcinomas of the gastrointestinal tract. Histopathology 2003, 42:137-140

27. Chu P, Wu E, Weiss LM: Cytokeratin 7 and cytokeratin 20 expression in epithelial neoplasms: a survey of 435 cases. Mod Pathol 2000, 13:962-972.

28. Poizat F, Gonzalez AM, Raynaud P, Baldet P, Garrel R, Crampette L, Costes V: Adenocarcinomas of nasal cavities and paranasal sinuses: diagnostic pitfalls in sinonasal glandular lesions. Ann Pathol 2009, 29:286-295.

doi:10.1186/1477-7819-11-114

Cite this article as: Wang and Chen: Palatine tonsillar metastasis of rectal adenocarcinoma: a case report and literature review. World Journal of Surgical Oncology 2013 11:114.

\section{Submit your next manuscript to BioMed Central and take full advantage of:}

- Convenient online submission

- Thorough peer review

- No space constraints or color figure charges

- Immediate publication on acceptance

- Inclusion in PubMed, CAS, Scopus and Google Scholar

- Research which is freely available for redistribution 